\title{
Produtividade e qualidade do feijoeiro cultivado sobre palhadas de gramíneas e adubado com nitrogênio em plantio direto
}

\author{
Camila Baptista do Amaral(1), Carolina Cipriano Pinto(1), Jordana de Araújo Flôres ${ }^{(1)}$, \\ Fábio Luiz Cecchio Mingotte(1), Leandro Borges Lemos ${ }^{(1)}$ e Domingos Fornasieri Filho ${ }^{(1)}$
}

(1)Universidade Estadual Paulista, Faculdade de Ciências Agrárias e Veterinárias, Campus de Jaboticabal, Via de Acesso Prof. Paulo
Donato Castellane, s/nº, CEP 14884-900 Jaboticabal, SP, Brasil. E-mail: camila.agro07@gmail.com, carolina.ccp@hotmail.com,
jordana_flores@hotmail.com, flcmingotte@gmail.com, leandrobl@fcav.unesp.br, fornasieri@fcav.unesp.br

Resumo - O objetivo deste trabalho foi avaliar a influência de doses de nitrogênio em cobertura e das palhadas de milho, de milho consorciado com braquiária e de braquiária sobre a produtividade e a qualidade de grãos do feijoeiro. O experimento foi realizado em área irrigada, no cultivo de inverno, após cinco anos da implantação do sistema plantio direto, em Latossolo Vermelho eutroférrico de textura argilosa. Utilizou-se o delineamento de blocos ao acaso com parcelas subdivididas e três repetições. As parcelas foram constituídas por palha de milho, palha de milho consorciado com braquiária e palha de braquiária; enquanto as subparcelas, pelas doses de $\mathrm{N}$ em cobertura correspondentes a $0,40,80,120$ e $160 \mathrm{~kg} \mathrm{ha}^{-1}$. Todos os tratamentos receberam $17 \mathrm{~kg}^{1} \mathrm{a}^{1}$ de $\mathrm{N}$ na semeadura. $\mathrm{O}$ feijoeiro cultivado sobre palha de braquiária atinge maior produtividade de grãos e maior eficiência agronômica. Os atributos qualitativos dos grãos não são alterados pelas diferentes palhadas avaliadas. A aplicação do $\mathrm{N}$ em cobertura aumentou o teor de proteína bruta e o tempo de cozimento dos grãos de feijão, além da produtividade de grãos do feijoeiro até a dose de $136 \mathrm{~kg} \mathrm{ha}^{-1}$ de N.

Termos para indexação: Phaseolus vulgaris, Urochloa ruziziensis, Zea mays, cultivos de cobertura, eficiência agronômica, feijoeiro irrigado, tempo de cozimento.

\section{Yield and quality of common bean cultivated on grass straws and fertilized with nitrogen under no-tillage}

\begin{abstract}
The objective of this work was to evaluate the effect of top-dressed nitrogen fertilization and of the straws of corn crop, of corn intercropped with Brachiaria, and of Brachiaria on grain yield and quality of common bean. The experiment was carried out under irrigation, in winter cropping, after five years from the implementation of a no-tillage system, in a clayey Oxisol. A randomized block design with split plots and three replicates was used. The plots consisted of the straws of corn, of corn intercropped with Brachiaria, and of Brachiaria; while the split plots consisted of top-dressed $\mathrm{N}$ at levels corresponding to $0,40,80,120$, and $160 \mathrm{~kg} \mathrm{ha}^{-1}$. All the treatments received $17 \mathrm{~kg} \mathrm{ha}^{-1} \mathrm{~N}$ at sowing. Common bean cropped over Brachiaria straw reaches higher grain yield and has increased agronomic efficiency. The evaluated straws did not affect the qualitative attributes of common beans. The application of top-dressed $\mathrm{N}$ increased protein contents and cooking time of the beans, besides grain yield up to the level of $136 \mathrm{~kg} \mathrm{ha}^{-1} \mathrm{~N}$.
\end{abstract}

Index terms: Phaseolus vulgaris, Urochloa ruziziensis, Zea mays, cover crops, agronomic efficiency, irrigated common beans, cooking time.

\section{Introdução}

Produzir alimentos com sustentabilidade é o maior desafio da agricultura nos próximos anos e, para isso, o sistema plantio direto (SPD) tem se destacado. O SPD aumenta a eficiência energética do sistema de produção (Rusu, 2014), e o não revolvimento do solo, preconizado por este manejo, promove maior conservação de nitrogênio, potássio e carbono no sistema solo-planta (Villamil \& Nafziger, 2015). Além disso, o SPD aumenta a matéria orgânica do solo, a porosidade total e o conteúdo de água disponível (Jemai et al., 2013), além de controlar o escorrimento superficial (Awale, 2013) e diminuir as perdas de solo. 
Para que os benefícios do SPD sejam atingidos, é importante que não ocorra revolvimento do solo, que se adote a rotação de culturas e que a palhada dos cultivos permaneça sobre a superfície do solo. Esses pré-requisitos, no entanto, representam um problema em regiões de clima tropical, pois as condições de alta temperatura e umidade favorecem a rápida decomposição dos resíduos vegetais (Butenschoen et al., 2011). Nesse sentido, a utilização de espécies com maior persistência no solo tem sido associada ao sucesso do SPD nessas regiões. A braquiária (Urochloa ruziziensis) e o milho (Zea mays), em cultivo solteiro ou consorciado (Silveira et al., 2011; Calonego et al., 2012; Garcia et al., 2014), têm sido amplamente estudados para este fim por apresentarem, principalmente, elevada produção de palha (Costa et al., 2012).

O tipo de palha presente na superfície do solo pode influenciar o manejo das culturas e, especialmente, o da adubação nitrogenada. No início do SPD, a imobilização de nutrientes e matéria orgânica no solo tende a ser maior que a mineralização, o que, no entanto, é alterado com o tempo, que aumenta a taxa de mineralização (Siqueira Neto et al., 2010). Essas características do sistema podem interferir na produtividade das culturas e na eficiência agronômica da adubação, especialmente no caso de espécies pouco eficientes na fixação biológica do nitrogênio, como o feijoeiro (Brito et al., 2011).

Nesse sentido, além de aumentar a produtividade da cultura, a adubação nitrogenada também pode ser uma alternativa para incrementar o teor de proteína nos grãos de feijão (Farinelli \& Lemos, 2010). Após a absorção pelas raízes, o $\mathrm{N}$ se combina com compostos orgânicos para a formação de aminoácidos, que dão origem às proteínas que se acumulam nos grãos (Perez et al., 2013). Todavia, pouco se sabe sobre a influência dos fatores palha e adubação nitrogenada sobre a qualidade dos grãos, bem como sobre a relação do teor de proteína com os outros atributos qualitativos do feijoeiro, como tempo de cozimento e tempo para máxima hidratação (Silva et al., 2006; Farinelli \& Lemos, 2010; Fiorentin et al., 2011).

O objetivo deste trabalho foi avaliar a influência das palhadas de milho, de milho consorciado com braquiária e de braquiária, bem como a de doses de $\mathrm{N}$ em cobertura, sobre a produtividade e a qualidade de grãos da cultura do feijoeiro (Phaseolus vulgaris L.).

\section{Material e Métodos}

O experimento foi realizado no ano agrícola 2013/2014, no município de Jaboticabal, SP (21 ${ }^{\circ} 14^{\prime} 33^{\prime}$ 'S, 48 ${ }^{\circ} 17^{\prime} 10^{\prime \prime} \mathrm{W}$ e altitude média de $\left.565 \mathrm{~m}\right)$. O clima predominante na região é o Aw, de acordo com a classificação de Köppen: tropical úmido com estação chuvosa no verão, e seca no inverno.

A área experimental encontrava-se sob SPD desde o verão da safra 2008/2009, tendo-se utilizado, ao longo do período, as sucessões: milho e feijoeiro; milho consorciado com braquiária e feijoeiro; braquiária e feijoeiro, com as gramíneas cultivadas no verão e o feijoeiro no inverno-primavera.

O solo da área experimental é um Latossolo Vermelho eutroférrico. Antes da semeadura do feijoeiro, realizou-se a amostragem no solo nas parcelas experimentais, na camada de $0,0-0,20 \mathrm{~m}$ de profundidade, tendo-se obtido os seguintes resultados: $\mathrm{pH}\left(\mathrm{CaCl}_{2}\right), 5,6$; matéria orgânica, $26 \mathrm{~g} \mathrm{~kg}^{-1}$; $\mathrm{P}$ (resina), $55 \mathrm{mg} \mathrm{dm}^{-3}$; H+Al, $28 \mathrm{mmol}_{\mathrm{c}} \mathrm{dm}^{-3} ; \mathrm{K}, 5,1 \mathrm{mmol}_{\mathrm{c}} \mathrm{dm}^{-3} ; \mathrm{Ca}, 44 \mathrm{mmol}_{\mathrm{c}} \mathrm{dm}^{-3}$, $\mathrm{Mg}, 30 \mathrm{mmol}_{\mathrm{c}} \mathrm{dm}^{-3}$; CTC, 107,1 $\mathrm{mmol}_{\mathrm{c}} \mathrm{dm}^{-3} \mathrm{e} \mathrm{V}, 74 \%$.

$\mathrm{O}$ delineamento experimental utilizado foi o de blocos ao acaso, com três repetições, em esquema de parcelas subdivididas. As parcelas foram constituídas de palhadas de milho, de milho consorciado com braquiária e de braquiária. As subparcelas $(3,6 \times 5 \mathrm{~m})$ foram constituídas de cinco doses de $\mathrm{N}$, aplicadas em cobertura: $0,40,80,120$ e $160 \mathrm{~kg} \mathrm{ha}^{-1} \mathrm{de} \mathrm{N}$, via ureia, no estádio V4-4. $\mathrm{O} \mathrm{N}$ foi aplicado manualmente aos 36 dias após a semeadura (estádio $\mathrm{V}_{4-4}$ ), na forma de ureia, em filete contínuo.

A semeadura das gramíneas foi realizada em 07/12/2012. O milho (híbrido simples AG 7088 VTPRO 2), tanto em cultivo solteiro como no consórcio, foi semeado no espaçamento entre linhas de $0,90 \mathrm{~m}$, na densidade de 66.000 plantas ha ${ }^{-1}$. No consórcio, a braquiária (Urochloa ruziziensis cv. Comum) foi semeada simultaneamente ao milho, nas entrelinhas, em fileira dupla com espaçamento de 0,22 m. Na semeadura da braquiária, utilizou-se 400 pontos de valor cultural, no total de $10 \mathrm{~kg} \mathrm{ha}^{-1}$ de sementes.

A adubação de semeadura do milho solteiro e do consorciado foi feita com $330 \mathrm{~kg} \mathrm{ha}^{-1}$ do formulado comercial 08-28-16. Nesses sistemas de cultivo, a adubação de cobertura foi realizada nos estádios fenológicos $\mathrm{V}_{4}$ e $\mathrm{V}_{8}$, tendo-se aplicado $400 \mathrm{~kg} \mathrm{ha}^{-1}$ do formulado $\mathrm{N}-\mathrm{P}_{2} \mathrm{O}_{5}-\mathrm{K}_{2} \mathrm{O} 20-0-20$ e $80 \mathrm{~kg} \mathrm{ha}^{-1}$ de $\mathrm{N}$, na 
forma de ureia, respectivamente. O cultivo solteiro da braquiária não recebeu adubação.

A colheita do milho foi realizada em 25/05/2013, tendo-se utilizado glifosato potássico $\left(1.860 \mathrm{~g} \mathrm{ha}^{-1} \mathrm{de}\right.$ i.a.) e carfentrazona etílica ( $40 \mathrm{~mL} \mathrm{ha}^{-1}$ de i.a.) para a dessecação, em 13/07/2013.

O feijoeiro foi semeado em 02/08/2013, com a cultivar IPR Andorinha, de hábito de crescimento determinado (tipo I), ciclo precoce e grãos do grupo comercial carioca, no espaçamento de $0,45 \mathrm{~m}$ entre linhas, com 12 sementes por metro de sulco, para garantir população de 260.000 plantas ha ${ }^{-1}$. A adubação de semeadura foi constituída de $210 \mathrm{~kg} \mathrm{ha}^{-1}$ do formulado comercial 8-28-16, e a emergência das plântulas ocorreu em 06/08/2013.

A adubação de cobertura foi feita em 16/09/2013, quando as plantas encontravam-se no estádio $\mathrm{V}_{4-4}$ (quarta folha trifoliada totalmente expandida). A aplicação de $\mathrm{N}$ foi realizada na superfície da palha, em filete contínuo, sem incorporação mecânica. Após a adubação, foi aplicada lâmina de $10 \mathrm{~mm}$ de irrigação. A cultura foi irrigada durante todo o ciclo, com lâminas entre 10 e $50 \mathrm{~mm}$ a cada 4 a 6 dias, conforme recomendações de Pavani et al. (2008).

Aos sete dias antes da semeadura do feijoeiro, foi efetuada amostragem da palha das gramíneas dessecadas. A quantidade total de palha $\left(\mathrm{Mg} \mathrm{ha}^{-1}\right)$ foi determinada com o auxílio de um quadrado de $0,25 \mathrm{~m}^{2}$, para coleta dos resíduos na superfície do solo, em dois pontos por subparcela. As amostras foram lavadas em água destilada e secadas em estufa a $65^{\circ} \mathrm{C}$, por 72 horas. Os teores de $\mathrm{C}$ e de $\mathrm{N}(\%)$ foram determinados com o método modificado de combustão em mufla e de destilação, respectivamente.

Por ocasião da colheita (30/10/2013), foi feito o arranquio manual das plantas, tendo-se utilizado trilha mecanizada. Após a secagem e limpeza, os grãos foram pesados para cálculo da produtividade $\left(\mathrm{kg} \mathrm{ha}^{-1} \mathrm{a}\right.$ $13 \%$ base úmida). Determinou-se eficiência agronômica $\left(\mathrm{kg} \mathrm{kg}^{-1}\right)$ da adubação nitrogenada em cobertura no feijoeiro, nas diferentes sucessões, de acordo com a metodologia proposta por Fageria \& Baligar (2005).

Os grãos recém-colhidos foram separados em peneira de furos oblongos $12 / 64$ " x $3 / 4$ ", e utilizados para a determinação dos atributos qualitativos. A partir da digestão dos grãos, os teores de $\mathrm{N}$ foram determinados, tendo-se estimado o teor de proteína bruta por meio da expressão: $\mathrm{N}$ total nos grãos $\mathrm{x}$ 6,25 . O tempo de cozimento ( $\mathrm{min}$ ) foi avaliado com o auxílio do cozedor de Mattson, com hidratação prévia dos grãos em água deionizada, durante 16 horas. $\mathrm{O}$ tempo para máxima hidratação (horas:minutos) foi determinado conforme Farinelli \& Lemos (2010).

Os dados foram submetidos à análise de variância e as médias foram comparadas com o teste de Tukey, a 5\% de probabilidade, exceto para relação C:N e eficiência agronômica. Os efeitos significativos das doses de $\mathrm{N}$ e da interação entre tipo de palhada $\mathrm{x}$ dose de $\mathrm{N}$ foram avaliados por meio de regressão polinomial. Realizou-se, ainda, o estudo de regressão polinomial entre o tempo de hidratação (horas) e a capacidade de hidratação dos grãos $(\mathrm{mL})$, a fim de determinar o tempo necessário para que ocorra a máxima hidratação dos grãos.

\section{Resultados e Discussão}

O cultivo exclusivo de braquiária proporcionou a maior quantidade de palha no momento da semeadura do feijoeiro, enquanto o consórcio resultou em quantidade intermediária, e o milho apresentou a menor produção de palhada (Figura 1). A relação $\mathrm{C}: \mathrm{N}$ da palha de milho foi superior à da palha de U. ruziziensis, o que a caracterizou como material de decomposição mais lenta e gradual. Segundo Cantarella et al. (2007), valores de relação C:N entre 12 e 25 favorecem a mineralização, enquanto valores maiores que 50 favorecem a imobilização; o equilíbrio nos dois processos seria atingido com valores de relação $\mathrm{C}: \mathrm{N}$ entre 25 e 30.

A produtividade de grãos foi maior com cultivo do feijoeiro sobre palha de $U$. ruziziensis, tendo alcançado $2.820 \mathrm{~kg} \mathrm{ha}^{-1}$, e a dos demais tratamentos não diferiu significativamente entre si (Figura 2). Resultados semelhantes foram encontrados por Sabundjian et al. (2013), que verificaram maior produtividade do feijoeiro sobre palha de $U$. ruziziensis. A maior produtividade observada nesse sistemas de cultivo, deve-se, entre outros fatores, aos efeitos positivos dessa forrageira sobre as características físico-químicas do solo e também à sua reduzida relação C:N. Silveira et al. (2011) verificaram produtividade de grãos de $2.310 \mathrm{~kg} \mathrm{ha}^{-1}$, no feijoeiro cultivado em sucessão a $U$. ruziziensis; essa produtividade foi associada ao aumento dos agregados do solo na camada de $0,0-0,20 \mathrm{~m}$, explicado pela alta densidade de raízes e o alto teor de lignina da matéria vegetal, que favorecem a estruturação e a estabilidade dos agregados do solo. Além disso, esta forrageira 
apresenta elevada liberação de nutrientes, em especial de N (Borges et al., 2014), fósforo e potássio (Pacheco et al., 2011).

A eficiência agronômica do $\mathrm{N}$ em cobertura variou em função do tipo de palha presente na superfície do solo (Figura 2). Os maiores valores foram observados no feijoeiro cultivado após a $U$. ruziziensis exclusiva, tendo-se observado diminuição da eficiência no cultivo consorciado e no milho exclusivo. Esse resultado pode ser atribuído à menor competição dos microrganismos pelo $\mathrm{N}$ durante o processo de decomposição da palha, visto que a relação $\mathrm{C}: \mathrm{N}$ de 26 , encontrada no sistema de cultivo com braquiária solteira, favorece a mineralização (Cantarella et al., 2007). Além disso, em solos sob palha de braquiária, a emissão de óxido nitroso é menor (Cruvinel et al., 2011), o que pode resultar em menores perdas de $\mathrm{N}$ por volatilização.
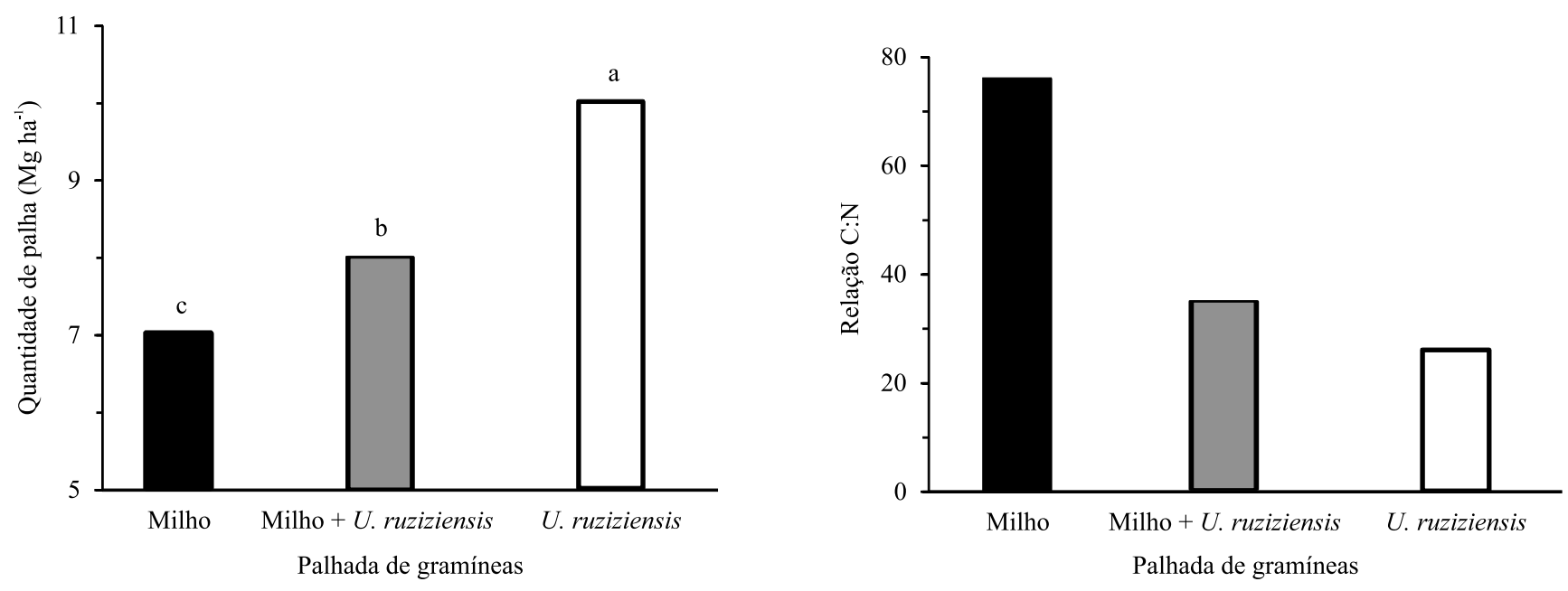

Figura 1. Produção de palhada e respectivos valores da relação C:N obtidos com os sistemas de cultivo com milho solteiro, milho consorciado com Urochloa ruziziensis e pastagem de Urochla ruziziensis, antes da semeadura do feijoeiro (Phaseolus vulgaris). Médias seguidas de letras iguais não diferem pelo teste de Tukey, a 5\% de probabilidade.
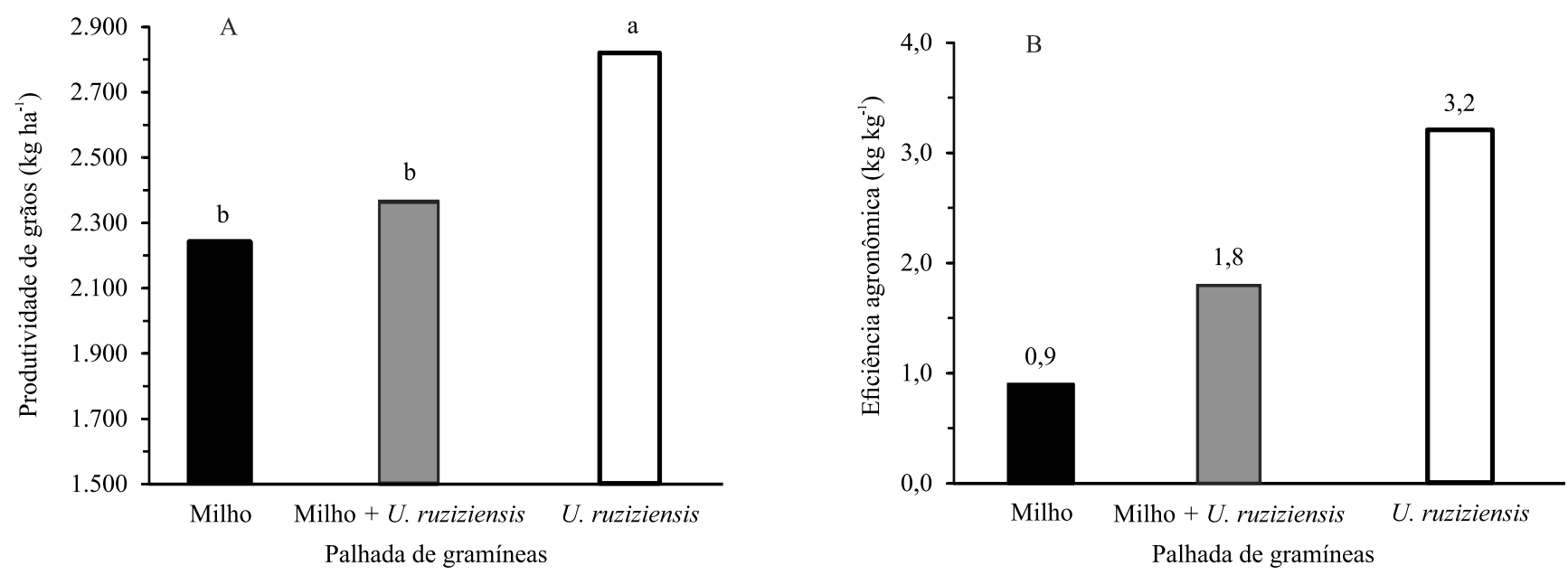

Figura 2. Produtividade de grãos (A) de feijoeiro (Phaseolus vulgaris) e eficiência agronômica da aplicação de N em cobertura (B) em função do tipo de palhada utilizado. Médias seguidas de letras iguais não diferem pelo teste de Tukey, a $5 \%$ de probabilidade. 
As doses de $\mathrm{N}$ em cobertura tiveram efeito sobre a produtividade do feijoeiro, e os resultados ajustaramse ao modelo quadrático (Figura 3). A máxima produtividade de grãos $\left(2.565 \mathrm{~kg} \mathrm{ha}^{-1}\right)$ foi obtida com aplicação de $136 \mathrm{~kg} \mathrm{ha}^{-1}$ de N. Souza \& Soratto (2012) verificaram resposta do feijoeiro a doses de $\mathrm{N}$ apenas em sucessão a milho consorciado com U. brizantha, com a maior produtividade obtida pela aplicação de $113 \mathrm{~kg} \mathrm{ha}{ }^{-1}$ de N. Mingotte et al. (2014) observaram que, no segundo ano de SPD, a adubação nitrogenada somente influenciou a produtividade do feijoeiro quando em sucessão ao milho solteiro, e as maiores produtividades foram obtidas sobre U. ruziziensis

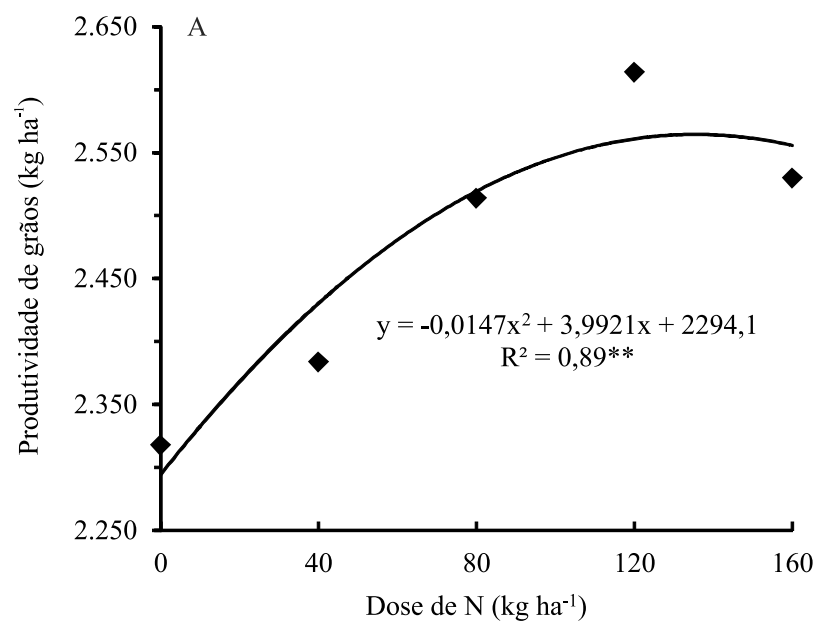

Figura 3. Produtividade de grãos (A) e eficiência agronômica (B) em função das doses de $\mathrm{N}$ aplicadas em cobertura no feijoeiro. **Significativo a $1 \%$ pelo teste $t$.
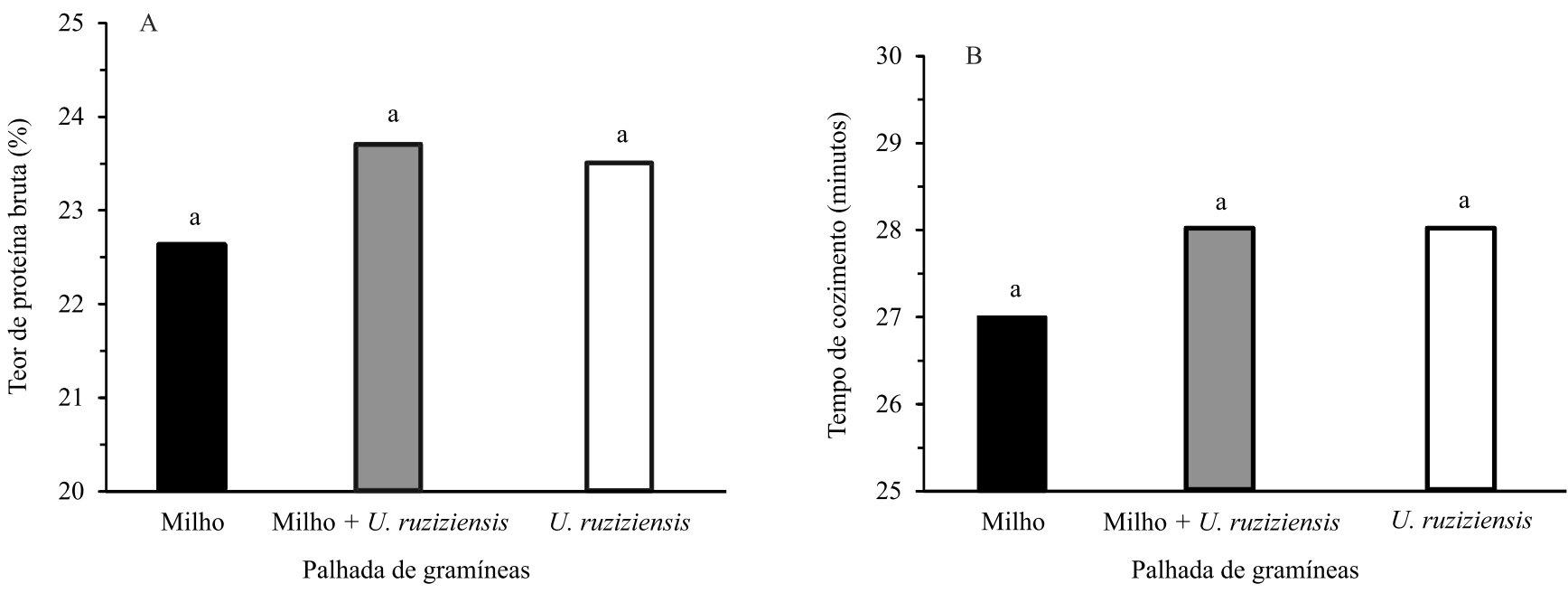

Figura 4. Teor de proteína bruta (A) e tempo de cozimento (B) de grãos de feijão em função do tipo de palhada avaliado. Médias seguidas de letras iguais não diferem pelo teste de Tukey, a 5\% de probabilidade. 
teor de proteína bruta, tempo de cozimento (Figura 4) e tempo para máxima hidratação (Tabela 1). Essa última variável, no entanto, foi influenciada pela interação entre os fatores. As doses de $\mathrm{N}$ aumentaram o teor de proteína bruta nos grãos, e os resultados ajustaram-se ao modelo linear crescente (Figura 5), similarmente aos resultados reportados por Farinelli \& Lemos (2010).

As doses de $\mathrm{N}$ em cobertura também tiveram influência sobre o tempo de cozimento dos grãos, com os resultados ajustados à função linear (Figura 5). Segundo a classificação de Proctor \& Watts (1987), para doses acima de $120 \mathrm{~kg} \mathrm{ha}^{-1}$, os grãos de feijão foram classificados como de resistência média ao cozimento; em doses inferiores, no entanto, foram classificados como de resistência normal ao cozimento. Todavia, o tempo de cozimento foi inferior a $30 \mathrm{~min}$ - preconizado como ideal por Ramalho \& Abreu (2006) - em todos os tratamentos. Silva et al. (2006) avaliaram o efeito da adubação com N em cobertura nos atributos qualitativos de grãos de feijão cultivado sob SPD e também observaram que o tempo de cozimento aumentou com as doses de $\mathrm{N}$ em cobertura. Esse resultado pode ser explicado pelo alto

Tabela 1. Tempo para máxima hidratação de grãos (Tmax) de feijoeiro, em função de doses de $\mathrm{N}$ em cobertura, aplicadas sobre palhadas de diferentes sistemas de cultivo de gramíneas.

\begin{tabular}{|c|c|c|c|}
\hline $\begin{array}{l}\text { Dose de N } \\
\left(\mathrm{kg} \mathrm{ha}^{1}\right)\end{array}$ & Hidratação em função do tempo & $\mathrm{R}^{2}$ & $\begin{array}{c}\text { Tmax } \\
\text { (h:min) }\end{array}$ \\
\hline & \multicolumn{3}{|l|}{ Milho solteiro } \\
\hline 0 & $y=-0,0001 x^{2}+0,1151 x+9,5906$ & $0,91 * *$ & $13: 54$ \\
\hline 40 & $y=-0,0001 x^{2}+0,1105 x+9,6444$ & $0,90 * *$ & $13: 43$ \\
\hline 80 & $y=-0,0001 x^{2}+0,1090 x+8,6241$ & $0,91 * *$ & $13: 52$ \\
\hline 120 & $y=-0,0001 x^{2}+0,1128 x+9,4301$ & $0,90 * *$ & $13: 48$ \\
\hline \multirow[t]{2}{*}{160} & $\mathrm{y}=-0,0001 \mathrm{x}^{2}+0,1054 \mathrm{x}+7,8111$ & $0,92 * *$ & $14: 26$ \\
\hline & \multicolumn{3}{|c|}{ Milho consorciado com Urochloa ruziziensis } \\
\hline 0 & $y=-0,0001 x^{2}+0,1098 x+8,7895$ & $0,91 * *$ & $13: 52$ \\
\hline 40 & $y=-0,0001 x^{2}+0,1123 x+8,2351$ & $0,93 * *$ & $13: 59$ \\
\hline 80 & $y=-0,0001 x^{2}+0,1109 x+9,0372$ & $0,90 * *$ & $13: 32$ \\
\hline 120 & $y=-0,0001 x^{2}+0,1066 x+8,6500$ & $0,91 * *$ & $14: 54$ \\
\hline \multirow[t]{2}{*}{160} & $y=-0,0001 x^{2}+0,1160 x+8,4321$ & $0,92 * *$ & $13: 41$ \\
\hline & \multicolumn{3}{|c|}{ Pastagem de Urochloa ruziziensis } \\
\hline 0 & $y=-0,0001 x^{2}+0,1043 x+8,9272$ & $0,90 * *$ & $13: 55$ \\
\hline 40 & $y=-0,0001 x^{2}+0,1116 x+9,2788$ & $0,90 * *$ & $13: 25$ \\
\hline 80 & $y=-0,0001 x^{2}+0,1132 x+9,3199$ & $0,90 * *$ & $13: 32$ \\
\hline 120 & $y=-0,0001 x^{2}+0,1065 x+9,1320$ & $0,91 * *$ & $14: 04$ \\
\hline 160 & $y=-0,0001 x^{2}+0,1104 x+8,5220$ & $0,92 * *$ & $13: 28$ \\
\hline
\end{tabular}

\footnotetext{
${ }^{* *}$ Significativo a $1 \%$ pelo teste $\mathrm{t}$.
}

peso molecular das proteínas (Neves et al., 2006), cujo aumento do conteúdo nos grãos dificultaria o processo de cozimento dos grãos.

Não se observou alteração no tempo para máxima hidratação com o incremento das doses de $\mathrm{N}$, e a máxima hidratação ocorreu entre 13 e 15 horas após a embebição (Tabela 1). Esse tempo foi superior ao obtido por Fiorentin et al. (2011), de 8:55 horas, na cultivar Pérola, em sucessão a milho solteiro, o que
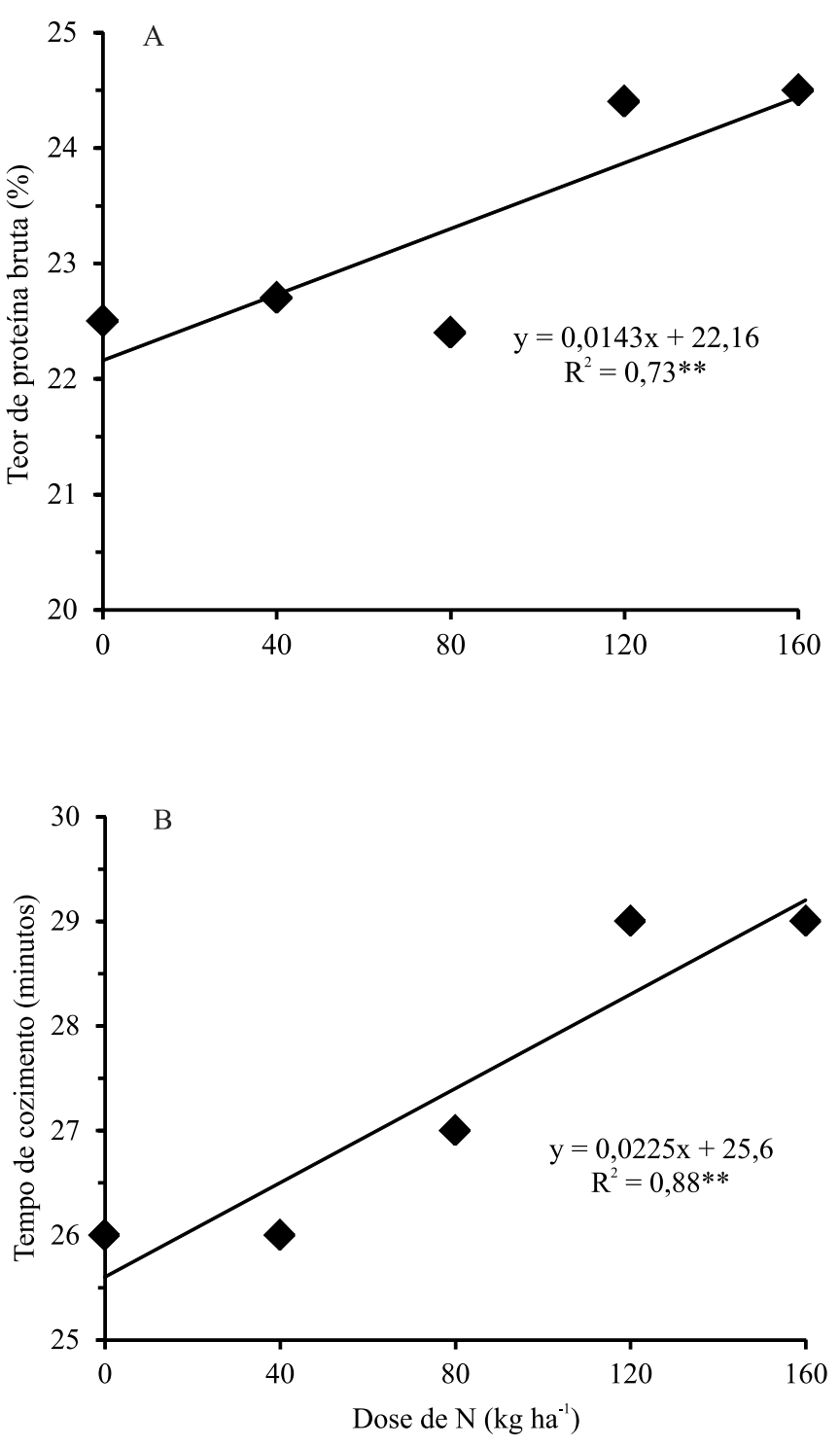

Figura 5. Teor de proteína bruta (A) e tempo de cozimento (B) de grãos de feijão em função das doses de $\mathrm{N}$ aplicadas em cobertura. ${ }^{* *}$ Significativo a $1 \%$ pelo teste $\mathrm{t}$.

Pesq. agropec. bras., Brasília, v.51, n.9, p.1602-1609, set. 2016 DOI: $10.1590 / \mathrm{S} 0100-204 X 2016000900060$ 
evidencia a necessidade de mais pesquisas sobre esse atributo qualitativo.

\section{Conclusões}

1. O cultivo do feijoeiro é beneficiado pela palhada de Urochloa ruziziensis, que proporciona maiores produtividades de grãos e eficiência agronômica.

2. A aplicação de $\mathrm{N}$ em cobertura aumenta a produtividade do feijoeiro até a dose de $136 \mathrm{~kg} \mathrm{ha}^{-1}$ de N.

3. Os atributos qualitativos dos grãos não são alterados pelas diferentes palhadas avaliadas.

4. A aplicação do $\mathrm{N}$ em cobertura aumenta o teor de proteína bruta e o tempo de cozimento dos grãos de feijão.

\section{Agradecimentos}

À Coordenação de Aperfeiçoamento Pessoal de Nível Superior (Capes), pela concessão de bolsa à primeira autora.

\section{Referências}

AWALE, R.; CHATTERJEE, A.; FRANZEN, D. Tillage and $\mathrm{N}$-fertilizer influences on selected organic carbon fractions in a North Dakota silty clay soil. Soil and Tillage Research, v.134, p.213-222, 2013. DOI: 10.1016/j.still.2013.08.006.

BORGES, W.L.B.; FREITAS, R.S. de; MATEUS, G.P.; SÁ, M.E. de; ALVES, M.C. Absorção de nutrientes e alterações químicas em Latossolos cultivados com plantas de cobertura em rotação com soja e milho. Revista Brasileira de Ciência do Solo, v.38, p.252-261, 2014. DOI: 10.1590/S0100-06832014000100025.

BRITO, M. de M.P.; MURAOKA, T.; SILVA, E.C. da. Contribuição da fixação biológica de nitrogênio, fertilizante nitrogenado e nitrogênio do solo no desenvolvimento de feijão e caupi. Bragantia, v.70, p.206-215, 2011. DOI: 10.1590/S000687052011000100027.

BUTENSCHOEN, O.; SCHEU, S.; EISENHAUER, N. Interactive effects of warming, soil humidity and plant diversity on litter decomposition and microbial activity. Soil Biology and Biochemistry, v.43, p.1902-1907, 2011. DOI: 10.1016/j. soilbio.2011.05.011.

CALONEGO, J.C.; GIL, F.C.; ROCCO, V.F.; SANTOS, E.A. dos. Persistência e liberação de nutrientes da palha de milho, braquiária e labe-labe. Bioscience Journal, v.28, p.770-781, 2012.

CANTARELLA, H. Nitrogênio. In: NOVAIS, R.F. de; ALVARES V., V.H.; BARROS, N.F. de; FONTES, R.L.; CANTARUTTI, R.B.; NEVES, J.C.L. (Ed.). Fertilidade do Solo. Viçosa: Sociedade Brasileira de Ciência do Solo, 2007. v.1, p.375-470.
COSTA, N.R.; ANDREOTTI, M.; GAMEIRO, R. de A.; PARIZ, C.M.; BUZETTI, S.; LOPES, K.S.M. Adubação nitrogenada no consórcio de milho com duas espécies de braquiária em sistema plantio direto. Pesquisa Agropecuária Brasileira, v.47, p.10381047, 2012. DOI: 10.1590/S0100-204X2012000800003.

CRUVINEL, E.B.F.; BUSTAMANTE, M.M. da C.; KOZOVITS, A.R.; ZEPP, R.G. Soil emissions of $\mathrm{NO}, \mathrm{N}_{2} \mathrm{O}$ and $\mathrm{CO}_{2}$ from croplands in the savanna region of central Brazil. Agriculture, Ecosystems and Environment, v.144, p.29-40, 2011. DOI: 10.1016/j.agee.2011.07.016.

FAGERIA, N.K.; BALIGAR, V.C. Enhancing nitrogen use efficiency in crop plants. Advances in Agronomy, v.88, p.97-185, 2005. DOI: 10.1016/S0065-2113(05)88004-6.

FARINELLI, R.; LEMOS, L.B. Produtividade, eficiência agronômica, características nutricionais e tecnológicas do feijão adubado com nitrogênio em plantio direto e convencional. Bragantia, v.69, p.165-172, 2010. DOI: 10.1590/S0006-87052010000100021.

FIORENTIN, C.F.; LEMOS, L.B.; JARDIM, C.A.; FORNASIERI FILHO, D. Formação e manutenção de palhada de gramíneas concomitante a influência da adubação nitrogenada em cobertura no feijoeiro irrigado em sistema de semeadura direta. Bragantia, v.70, p.917-924, 2011. DOI: 10.1590/S0006-87052011000400026.

GARCIA, C.M. de P.; ANDREOTTI, M.; TEIXEIRA FILHO, M.C.M.; LOPES, K.S.M.; BUZETTI, S. Decomposição da palhada de forrageiras em função da adubação nitrogenada após o consórcio com milho e produtividade da soja em sucessão. Bragantia, v.73, p.143-152, 2014. DOI: 10.1590/brag.2014.016.

JEMAI, I.; AISSA, N.B.; GUIRAT, S.B.; BEN-HAMMOUDA, M.; GALLALI, T. Impact of three and seven years of no-tillage on the soil water storage, in the plant root zone, under a dry subhumid Tunisian climate. Soil and Tillage Research, v.126, p.26-33, 2013. DOI: 10.1016/j.still.2012.07.008.

MINGOTTE, F.L.C.; YADA, M.M.; JARDIM, C.A.; FIORENTIN, C.F.; LEMOS, L.B; FORNASIERI FILHO, D. Sistemas de cultivo antecessores e doses de nitrogênio em cobertura no feijoeiro em plantio direto. Bioscience Journal, v.30, p.696-706, 2014. Supplement 2.

NEVES, V.A.; SILVA JR., S.I.; SILVA, M.A. da. Isolamento da globulina majoritária, digestibilidade in vivo e in vitro das proteínas do tremoço-doce (Lupinus albus L.), var. Multolupa. Food Science and Technology, v.26, p.832-840, 2006. DOI: 10.1590/S0101-20612006000400019.

PACHECO, L.P.; BARBOSA, J.M.; LEANDRO, W.M.; MACHADO, P.L.O. de A.; ASSIS, R.L. de; MADARI, B.E.; PETTER, F.A. Produção e ciclagem de nutrientes por plantas de cobertura nas culturas de arroz de terras altas e de soja. Revista Brasileira de Ciência do Solo, v.35, p.1787-1799, 2011. DOI: 10.1590/S0100-06832011000500033.

PAVANI, L. C.; LOPES, A.S.; GALBEIRO, R.B. Manejo da irrigação na cultura do feijoeiro em sistemas plantio direto e convencional. Engenharia Agrícola, v.28, p.12-21, 2008. DOI: 10.1590/S0100-69162008000100002.

PEREZ, A.A.G.; SORATTO, R.P.; MANZATTO, N.P.; SOUZA, E. de F.C. de. Extração e exportação de nutrientes pelo feijoeiro adubado com nitrogênio, em diferentes tempos de 
implantação do sistema plantio direto. Revista Brasileira de Ciência do Solo, v.37, p.1276-1287, 2013. DOI: 10.1590/S010006832013000500017.

PROCTOR, J.R.; WATTS, B.M. Development of a modified Mattson Bean Cooker procedure based on sensory panel cookability evaluation. Canadian Institute of Food Science and Technology Journal, v.20, p.9-14, 1987. DOI: 10.1016/S03155463(87)70662-2.

RAMALHO, M.A.P.; ABREU, A.F.B. Cultivares. In: VIEIRA, C.; PAULA JÚNIOR, T.J.; BORÉM, A. Feijão. 2.ed. Viçosa: Ed. da UFV, 2006. cap. 14, p.415-436.

RUSU, T. Energy efficiency and soil conservation in conventional, minimum tillage and no-tillage. International Soil and Water Conservation Research, v.2, p.42-49, 2014. DOI: 10.1016/S20956339(15)30057-5.

SABUNDJIAN, M.T.; ARF, O.; KANEKO, F.H.; FERREIRA, J.P. Adubação nitrogenada em feijoeiro em sucessão a cultivo solteiro e consorciado de milho e Urochloa ruziziensis. Pesquisa Agropecuária Tropical, v.43, p.292-299, 2013. DOI: 10.1590/ S1983-40632013000300007.

SANT'ANA, E.V.P.; SANTOS, A.B. dos; SILVEIRA, P.M. da. Eficiência de uso de nitrogênio em cobertura pelo feijoeiro irrigado. Revista Brasileira de Engenharia Agrícola e
Ambiental, v.15, p.458-462, 2011. DOI: 10.1590/s141543662011000500004 .

SILVA, T.R.B. da; LEMOS, L.B.; TAVARES, C.A. Produtividade e característica tecnológica de grãos em feijoeiro adubado com nitrogênio e molibdênio. Pesquisa Agropecuária Brasileira, v.41, p.739-745, 2006. DOI: 10.1590/S0100-204X2006000500004.

SILVEIRA, P.M. da; SILVA, J.H. da; LOBO JUNIOR, M.; CUNHA, P.C.R. da. Atributos do solo e produtividade do milho e do feijoeiro irrigado sob sistema integração lavoura-pecuária. Pesquisa Agropecuária Brasileira, v.46, p.1170-1175, 2011. DOI: 10.1590/S0100-204X2011001000008.

SIQUEIRA NETO, M.; PICCOLO, M. de C.; VENZKE FILHO, S. de P.; FEIGL, B.J.; CERRI, C.C. Mineralização e desnitrificação do nitrogênio no solo sob sistema plantio direto. Bragantia, v.69, p.923-936, 2010. DOI: 10.1590/S0006-87052010000400019.

SOUZA, E. de F.C. de; SORATTO, R.P. Adubação nitrogenada no feijoeiro após milho safrinha consorciado com Urochloa brizantha e Urochloa ruziziensis. Semina: Ciências Agrárias, v.33, p.26692680, 2012. DOI: 10.5433/1679-0359.2012v33n6Supllp2669.

VILLAMIL, M.B.; NAFZIGER, E.D. Corn residue, tillage, and nitrogen rate effects on soil carbon and nutrient stocks in Illinois. Geoderma, v.253-254, p.61-66, 2015. DOI: 10.1016/j. geoderma.2015.04.002.

$\overline{\text { Recebido em } 31 \text { de agosto de } 2015 \text { e aprovado em } 9 \text { de maio de } 2016}$ 